\title{
Todo sobre mi madre, la mujer y los nuevos modelos familiares a través de la metaficción y la intertextualidad
}

\author{
Todo sobre mi madre, women and new family models through metafiction and \\ intertextuality
}

\section{Lucía Cabrera Romero ${ }^{1}$}

\begin{abstract}
RESUMEN
El objetivo de este trabajo es analizar el uso que el director de cine Pedro Almodóvar hace de recursos como la metaficción y la intertextualidad para retratar el universo femenino y presentar nuevos modelos familiares. Para ello, se toma el ejemplo de su obra cinematográfica Todo sobre mi madre y se analizan los mecanismos de metaficción a lo largo de la película, el papel que representan los personajes femeninos principales y los intertextos introducidos de diferentes ámbitos artísticos. Los resultados obtenidos muestran una reflexión sobre el acto creador; una nueva forma de narrar los hechos, donde la ficción se anticipa a la realidad de la película; y un modelo de familia diferente al tradicional. Los intertextos, además de caracterizar a los personajes, cobran un nuevo significado y presentan una maternidad que poco o nada tiene que ver con lo biológico. Palabras clave: Almodóvar, intertextualidad, metaficción, mujer, familia.
\end{abstract}

\begin{abstract}
The aim of this work is to analyse the use that the film director Pedro Almodóvar makes of resources such as metafiction and intertextuality to portray female universe and present new family models. His cinematographic work Todo sobre mi madre is taken as an example to analyse the mechanisms of metafiction throughout the film, the role played by the main female characters and the intertexts introduced from different artistic fields. The results show a reflection on creative act; a new way of narrating facts, where fiction anticipates the reality of the film; and a family model different from the traditional one. The intertexts, in addition to typify the characters, take on a new meaning and present a motherhood that has little or nothing to do with the biological.
\end{abstract}

Key Words: Almodóvar, intertextuality, metafiction, women, family.

\section{Introducción}

Es una constante en la obra de Almodóvar la reflexión sobre los propios mecanismos de ficción, poniendo al descubierto la artificiosidad y problematizando la barrera entre ficción y realidad; como muestra, se utilizará una de sus películas, Todo sobre mi madre (1999a), que, además, presenta numerosos intertextos referidos al mundo creativo -existen alusiones a la pintura, la arquitectura, la literatura y la escritura, el teatro y el cine- a los que Almodóvar da un nuevo significado. La base del término intertextualidad se encuentra en la teoría de Bajtín (1981) del discurso dialógico, que se

\footnotetext{
${ }^{1}$ Universidad de Córdoba, España. Investigadora, Departamento de Ciencias del Lenguaje. ORCID: https://orcid.org/0000-0002-9794-1565 Correo electrónico: lucia.cabrera@uco.es
} Recepción: 24/02/2019. Aceptación: 14/04/2020. 
refiere a las voces propias y ajenas; la repetición de un discurso ajeno en la realización de otro nuevo da origen a la intertextualidad. Fue Julia Kristeva la que, a partir de esta teoría, define el término de la siguiente manera: "Todo texto se construye como mosaico de citas, todo texto es absorción y transformación de otro texto" (1978, p. 190). ${ }^{2}$

Por otro lado, se entiende el concepto de metaficción como autorreflexión y autorreferencia, poniendo de manifiesto el artificio de la obra. Así lo define Patricia Waugh, dentro de la escuela anglosajona: “Aquellas obras de ficción que de forma autoconsciente y sistemática, llaman la atención sobre su condición de artificio creado para así plantear cuestiones sobre las relaciones entre ficción y realidad" $(1984$, p. 34$){ }^{3}$

Mediante los mecanismos de metaficción e intertextualidad anteriormente descritos, el director manchego muestra un nuevo modelo de familia, haciendo hincapié en la figura de la madre. De la misma manera, presenta una nueva forma de mostrar la vida; primero, se ve lo artificioso y luego la realidad, y esta última se verá transformada, a su vez, por la ficción. En estos términos entiende Almodóvar su manera de hacer cine y así lo expresa:

Se supone que la forma más directa de retratar la vida es la naturalista, la narración pegada a la realidad. En ese sentido yo no diría que retrato la vida, a pesar de que mis películas rebosen justo eso, vida, o mejor dicho, vitalidad. Para mí el cine es representación, el mejor modo de acercarme a la realidad es a través del artificio y la ficción. En mis películas la emoción está elaborada, no retratada, eso es lo que me atrae de hacer cine. Montar todo el tinglado para convocar emociones en las que me reconozco y espero que el público se reconozca también. Y eso es también realidad y vida, pero no como se percibe en un retrato naturalista, o en un documental (Sardá, 2008, p. 80).

\footnotetext{
${ }^{2}$ Otro trabajo clave para comprender el concepto de intertextualidad es Palimpsestes. La littérature au second dregré de Genette, donde se define intertextualidad como "una relación de copresencia entre dos o más textos" $(1989$, p. 10) o la presencia de un texto en otro.

${ }^{3}$ Además de la obra de Patricia Waugh, el número 208 de la Revista Anthropos: Huellas del conocimiento está dedicado a metaliteratura y metaficción, es de especial interés el artículo de Patricia Cifre Wibrow (2005) titulado "Metaficción y postmodernidad: interrelación entre dos conceptos problemáticos".
} 
Esta forma de retratar la vida a través del artificio se refleja desde el inicio de la obra, los mecanismos de metaficción empiezan cuando Manuela, la protagonista, y su hijo Esteban se sientan a ver una película en la televisión, que comienza tras el anuncio de unos pañales. La película, All about Eve (Joseph L. Mankiewicz [1950]), está traducida al español como Eva al desnudo. Esteban advierte que la traducción debería ser "Todo sobre Eva", y este título le da pie a titular así el relato que quiere escribir sobre su madre, dando lugar también al título de la película que el espectador está viendo. Se observa un plano en el que la pantalla se ha transformado en un cuaderno en blanco donde un lápiz, el de Esteban, escribe; en seguida, se ve el título de la película de Almodóvar como si fuera Esteban el que lo ha escrito en la pantalla. Este título, por tanto, actúa en dos niveles, conectando así a este joven creador con él mismo, el director de la película.

Manuela le ha contado a su hijo que actuó en el teatro de joven; por lo que, al introducir este intertexto cinematográfico, el espectador puede pensar que la película va a tratar sobre una joven (Eva Harrington es Manuela en la película de Almodóvar) que quiere introducirse en el mundo del espectáculo y para ello se hace amiga de una veterana actriz (Margo Channing es Huma en la película de Almodóvar), como ocurre en All about Eve. También el propio título de la película, Todo sobre mi madre, crea unas expectativas que no se cumplen. El chico muere antes de poder completar los escritos sobre Manuela, la película no es la historia de su madre. Como señala Siles Ojeda, "la historia de Todo sobre mi madre está narrada para que al final sea posible saber del padre" (2008, p. 161). La película es un ejemplo de intertextos premonitorios en la obra de Almodóvar:

La introducción de cine en la película misma, como premonición aclaratoria de lo que va a suceder, es también otra constante en la obra almodovariana. Tal es el caso de Matador, cuando los protagonistas se encuentran por vez primera en un cine donde se proyecta Duelo al sol, o la Eva al desnudo (esta vez cine televisado) premonitoria de Todo sobre mi madre (Colmenero Salgado, 2001, p. 23).

Sin embargo, el intertexto de Eva al desnudo está muy bien elegido, además de poner de relieve la artificiosidad del cine, titulando su película como la que están viendo los personajes, la película trata de actrices y mujeres. Este aspecto es el que le interesa a Almodóvar. El propio director dice, a propósito de la película de Mankiewicz: 
Mujeres que se confiesan y se mienten en el camerino de un teatro, convertido en una sancta sanctórum del universo femenino (equivale al patio de mi niñez. Tres o cuatro mujeres, hablando, significan para mí el origen de la vida, pero también el origen de la ficción, y de la narración) (Caparrós Lera, 2001, p. 45). ${ }^{4}$

Almodóvar habla también de la capacidad de la mujer para fingir, debido al machismo tenían que ocultar y mentir para que la vida siguiera su curso, y así lo manifiesta Manuela en cierto momento de la película.

\section{Mujeres $y$ actrices que hacen de actrices como muestra de}

\section{metaficcionalidad}

Manuela es una actriz que hace de actriz y, además, de madre. Estos serán los principales temas desarrollados en la película: la familia y la maternidad, así como la metaficción (actrices que hacen de actrices). Al titular la obra Todo sobre mi madre utilizando como intertexto All about Eve, conecta a la madre, Manuela, con Eva, la madre por antonomasia. Almodóvar dedica abiertamente esta película a las mujeres que actúan, a las madres y a las actrices que han hecho de actrices en el cine. El director suele recordar en sus textos escritos a numerosas artistas que han hecho de actrices a su vez, recalcando siempre su interés y su gusto por todo lo relacionado con el cine dentro del cine:

Siempre me han interesado las películas que reflejan el mundo del cine. No me refiero a las que hablan del lenguaje, sino a las que cuentan historias de actores, directores, escritores, productores, estilistas, maquilladores, figurantes, imitadores de estrellas, etc. Películas cuyo argumento es el propio cine, y las personas que lo hacen (Almodóvar, 1999b, p. 173).

Pero volviendo al papel de Manuela como actriz, hay otro mecanismo metaficcional que también se corresponde con un intertexto, esta vez, sacado de una de sus propias películas, La flor de

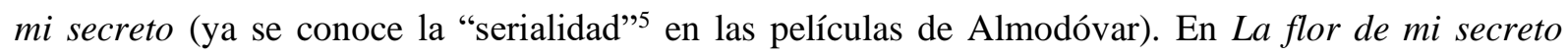

\footnotetext{
${ }^{4}$ Palabras de Pedro Almodóvar recogidas por José María Caparrós Lera en El cine de fin de milenio: 1999-2000.

${ }^{5}$ Término utilizado por Marsha Kinder y definido por Henry Jenkins (2011) como uno de los siete principios de la narrativa transmedia para referirse al desarrollo de una historia a lo largo del tiempo, generalmente a través de un proceso de división de la historia en fragmentos interconectados, como hace Pedro Almodóvar al presentar a personajes que aparecerán en posteriores películas.
} 
aparece un personaje llamado Manuela, que hace una simulación para un seminario sobre trasplantes, en la que los médicos le hablan sobre la posibilidad de donar los órganos de su hijo y así salvar la vida de otras personas. La misma escena ocurre en Todo sobre mi madre, donde se muestra un plano de los médicos y Manuela, posteriormente se observa que lo están viendo en una televisión y luego rebobinan la cinta, para recalcar más aún este carácter artificioso. Pero esta ficción se convierte en realidad en la película cuando Manuela firma una autorización para que donen los órganos de su hijo que acaba de tener el accidente. De nuevo, la ficción va antes que la realidad, el director muestra una grabación de Manuela haciendo un papel que momentos después se hará realidad en la película. El propósito de utilizar estos mecanismos lo explica Navarro-Daniels con estas palabras:

Las obras metaficcionales enfatizan su naturaleza ficcional para señalar las semejanzas entre la creación literaria y la creación de una vida. Los personajes, por ejemplo, se comprenden a sí mismos a partir del mundo del arte, y desde allí interpretan su propia historia y se proyectan hacia el futuro. De esta manera, el acto de escribir, actuar, o inventar un argumento les permite cobrar realidad (2002, p. 389).

Tras su muerte, Esteban cobrará vida en el cuaderno que escribía sobre su madre en el momento antes de morir.

Algunos críticos de Almodóvar ven en el tema del trasplante de órganos una referencia al hecho de la intertextualidad. Tal es el caso de Pedro Poyato, que afirma que "en el transplante se trata de absorber los signos de lo que no es propio, en este caso, el otro cuerpo" (2006, p. 59). Trasplantar cosas de un cuerpo a otro también tiene mucho que ver, por tanto, con la transexualidad, encarnada en esta película por Agrado, una transexual amiga de Manuela que la ayudará a buscar al padre de su hijo. Ella también utiliza un par de intertextos cuando se mira en el espejo y ve su cara hinchada: parezco $E l$ hombre elefante (David Lynch [1980]); y cuando ve a todas las chicas reunidas en el piso y dice que la situación le recuerda a Cómo casarse con un millonario (Jean Negulesco [1953]).

Además de colaborar con el seminario de trasplantes de órganos, se sabe que Manuela ha trabajado como actriz haciendo representaciones basadas en textos de Boris Vian y también ha hecho de Stella Dubois en una representación amateur de Un tranvía llamado deseo -intertexto y otra autorreferencia al artificio de la actuación-, donde conoció a su marido. Un tranvía llamado deseo es 
una obra de teatro de Tennessee Williams que fue llevada al cine en 1951 por Elia Kazan. Es la obra que Manuela y su hijo ven el día que atropellan a este. En la obra, es posible identificar a Manuela con Stella:

Manuela, así como Stella Dubois abandona a su esposo, teniendo ambas mujeres al hijo como ímpetu para semejante acción. Aunque no sabemos qué ocurre posteriormente con Stella, sí conocemos la historia de Manuela. Ésta, quien se identifica con Stella y se comprende a sí misma a la luz del personaje de Tennesse Williams, logra construir una familia nada convencional (Navarro-Daniels, 2002, p. 391).

De nuevo, la metaficción permite que el personaje de Manuela cobre sentido, lo que muestra, además, un nuevo modelo familiar, al que se hace referencia al final. La identificación entre Stella y Manuela cobra aún más fuerza cuando esta última interpreta a Stella por la ausencia de Nina -actriz que hacía de Stella en la obra teatral que van a ver madre e hijo-. Ficción y metaficción se mezclan en ese hermoso plano con Manuela y el cartel enorme de Blanche -en este caso, Huma, que es la actriz que hace de Blanche- a sus espaldas: "Desde el punto de vista de Esteban es como si Manuela se paseara por el rostro de Blanche, fundiéndose con ella" (Navarro-Daniels, 2002, p. 397).

En cuanto a Huma, se presentan dos identificaciones claras. Como siempre ocurre con Almodóvar, la ficción se anticipa a la realidad o, como en este caso, la metaficción se anticipa a la ficción. Tras la faceta de actriz de Huma, se conoce al personaje real. Ambos, Huma caracterizada de Blanche y el personaje de Huma creado por el director manchego, se conectan cuando la actriz se apropia de una de las frases de Blanche, fuera de los escenarios, al ser ayudada por Manuela: "Siempre he confiado en la bondad de los desconocidos". Como señala la autora Navarro-Daniels:

Ella es una nueva Blanche, la cual hace manifiesta su necesidad de los otros. Su tortuosa relación amorosa con Nina la acerca a Manuela, quien, en un primer encuentro, es esa persona extraña en quien Huma confía. [...] El guion señala que Huma no sólo hace suyas las palabras de Blanche, sino también su infinita fragilidad y agradecimiento (2002, p. 393).

Huma se identifica totalmente con el personaje que encarna, es más auténtica cuanto más imita. La otra identificación, como ya se señaló al principio, es con Margo Channing de All about Eve. Huma dice que se puso ese nombre por el humo, porque ella fuma a imitación de la actriz Bette Davis, 
curiosamente, la actriz que interpreta a Margo. De nuevo, retornan a la mente las conexiones de Huma -una actriz que actúa de actriz teatral, que también imita a otra actriz que interpretó el papel de una actriz en el cine- con Margo Channing y de Manuela con Eva Harrington. Al igual que le ocurre a Margo en All about Eve, Huma, tras el relato de Manuela sobre cómo murió su hijo, se da cuenta de que los admiradores como Esteban son personas individualizadas y no solo un grupo de fanáticos locos por conseguir un autógrafo.

Volviendo a Manuela y su identificación con el personaje de Stella, al igual que esta se va de casa, motivada por su hijo, Manuela huye a Madrid cuando queda embarazada para proteger al pequeño Esteban de su padre, Lola, personaje del que se hablará más adelante. Con un hermoso travelling $^{6}$ y una música extradiegética, ${ }^{7}$ a través del túnel, se observa la vuelta de Manuela a Barcelona en un tren o tranvía, ${ }^{8}$ siempre motivada por aspectos relacionados con su hijo. Como ella misma dice en la película: "Hubiera podido ser actriz, si hubiera querido. Pero mi única vocación ha sido cuidar de mis hijos". Manuela, como Eva, es la madre por excelencia en la película; aparte de los papeles en obras de teatro, actúa como madre de Rosa y se convierte luego en madre del Esteban recién nacido, hijo de Rosa.

Manuela, cuando no es actriz, sigue siendo un personaje de la obra de su hijo, aunque este ya no esté, es como si siguiera dictando su destino desde el más allá. Es por él por quien va a Barcelona. Esteban es como un pequeño dios que mueve la vida de su madre, un creador. La escritura de Esteban es otro mecanismo metaficticio, ya que reflexiona sobre el acto de crear. Al escribir sobre la pantalla se ve en primer plano el acto de la escritura. En otra escena, poco después de esta, la madre le regala Música para camaleones (1950) de Truman Capote, y le lee el prefacio, donde también se hace una reflexión sobre el acto de la escritura: "Cuando Dios le entrega a uno un don también le entrega un látigo y el látigo es únicamente para autoflagelarse". Este intertexto contribuye, por tanto, a la

\footnotetext{
${ }^{6}$ El travelling, o trávelin, en español, es un término cinematográfico que, según el Diccionario de la lengua española, se refiere al desplazamiento de la cámara mediante rieles para seguir los movimientos del objeto en cuestión, en este caso, un tren.

${ }^{7}$ Aquella que no pertenece al mundo de la ficción y se añade de manera artificial al desarrollo narrativo.

${ }^{8}$ Conectando así la escena con la representación de Un tranvía llamado deseo, en la que Manuela actuó y donde conoció a su marido.
} 
elaboración del personaje de Esteban como autor-creador que determina el destino del personaje de su madre.

\section{Construcción de nuevos modelos familiares a través de los intertextos}

En uno de esos viajes a Barcelona, Manuela pasa por el conocido templo de la Sagrada Familia (Antoni Gaudí). Este intertexto arquitectónico se combina con otros lugares de Barcelona, como la fachada del Palacio de la música (Doménech i Montaner) y la Barceloneta -en una fotografía donde aparecen Manuela y el padre de su hijo, que ahora se llama Lola-. Se observa la Sagrada Familia reflejada en el cristal de la ventanilla del coche y, al bajarse la ventanilla, se ve la cara de Manuela. Tiene mucho sentido relacionarlos porque esta fachada del monumento celebra la vida, el nacimiento de Jesús. Pero el modelo de la familia retratado por Gaudí será totalmente opuesto al modelo que Almodóvar propone en su película. En el momento en que Rosa dice: "Este niño va a ser de las dos”, Rosa y Manuela se convierten en las mamás del pequeño Esteban que va a nacer, no hay figura paterna. Más adelante, cuando Rosa muere, Manuela lleva al pequeño Esteban a que conozca a su padre; ha prometido a Rosa que no le ocultará nada y este es también su modo de contar la verdad a su hijo, ya que no pudo hacerlo con su hijo biológico. Lola -antes llamada Esteban- es el hombre que actúa como mujer, cuyo proceso de transformación se pone de manifiesto en la película cuando Agrado dice las siguientes palabras: "Nos pusimos las tetas juntas en París". Lola también es mujer sin serlo y termina siendo una tercera madre para el pequeño Esteban. Nunca pudo ejercer de padre del fallecido Esteban, pero cuenta que siempre quiso tener un hijo. A la abuela del niño no le gusta que Lola bese al pequeño Esteban, pero Manuela contesta: "Esa mujer es su padre". Esta frase sería impensable en un modelo tradicional de familia donde la mujer es la madre y el hombre es el padre. Pero Almodóvar ha cuestionado y replanteado este modelo haciendo que Esteban tenga tres madres; Rosa, Manuela y Lola. Es lo interesante de utilizar intertextos -como el de la Sagrada Familia-, Almodóvar recoge en su obra unos modelos, pero cuestionándolos, por lo que estos amplían su significado, creándose nuevos conceptos: "Todo sobre mi madre está construida como un permanente diálogo con obras anteriores, las cuales son traídas al filme en cuyo interior son transformadas y 
provistas de un nuevo sentido. Ahora bien, esto no impide que el significado original se pierda, sino que permanece transfigurado" (Navarro-Daniels, 2002, p. 410).

En cuanto a la abuela, la madre de Rosa, se presenta como la antítesis de Manuela. Manuela es mucho más madre para Rosa, como así lo sugieren los intertextos pictóricos introducidos. La madre de Rosa falsifica cuadros de Marc Chagall, procurando ocultar su actividad, en uno de los planos se ve un cuadro de la Virgen con el niño Jesús en brazos. La pintura, otro medio de creación, le sirve al director manchego para insinuar que la madre de Rosa es una "falsa madre", como las falsificaciones de los cuadros que pinta. Del mismo modo, los lazos familiares también parecen ser impostados, para mantener una normalidad aparente, frente a los lazos que se crean entre Rosa y Manuela, que sí son reales. Se está mostrando un nuevo modelo de maternidad, algo que no es biológico, que hay que “actuar" como madre para serlo de verdad, como Manuela hizo con Rosa. Manuela es la Madre por antonomasia, como Eva, ya que ha actuado o cumplido el papel de madre con su hijo biológico, con Rosa y con el hijo biológico de esta, y lo ha hecho porque lo ha decidido así, no porque le haya tocado.

La alusión a la sangre del hijo, que está infectada con el virus del VIH -y esto hace que la abuela lo rechace en cierta medida-, vuelve a conectar la obra con dos intertextos de Lorca: Bodas de Sangre (1933) y Yerma (1934). Se ve a Huma ensayando una obra de Lluís Pascual, Haciendo Lorca, de nuevo un mecanismo metaficcional. Esta obra, como bien ha señalado Navarro-Daniels o Pedro Poyato, entre otros, ensambla pasajes de ambas obras lorquianas. El texto recitado por Huma ante un teatro, vacío esta vez -solo Agrado y otra persona se encuentran en el público, puesto que es solo un ensayo- coincide con la huida a Madrid de Manuela. Por tanto, Almodóvar conecta el sacrificio de una madre que va a llevarse el niño para cuidar de él y protegerlo con el texto de Lorca que Huma recita en la película:

Hay gente que piensa que los hijos son cosa de un día. Pero se tarda mucho. Mucho. Por eso es tan terrible ver la sangre de un hijo derramada por el suelo. Una fuente que corre durante un minuto y a nosotras nos ha costado años. Cuando yo descubrí a mi hijo, estaba tumbado en mitad de la calle. Me mojé las manos de sangre y me las lamí con la lengua. Porque era mía. Los animales los lamen, ¿verdad? A mí no me da asco mi hijo (García Lorca, 2002, p. 91). Tú 
no sabes lo que es eso. En una custodia de cristal y topacios pondría yo la tierra empapada por su sangre. ${ }^{9}$

Es como si Manuela estuviera diciendo estas palabras a la abuela de Esteban, a ella no le da asco su sangre, aunque porte el virus. Es lo que convierte a Manuela en una verdadera madre:

La alusión a la sangre de la cual las madres lorquianas -incluso una madre sólo virtual, como lo es Yerma- declaran no sentir el menor resquemor, es el elemento que potencia y agranda la figura de Manuela y su amor hacia el tercer Esteban: tratándose de un niño infectado con el VIH, el impacto de "lamer con la lengua" la sangre del hijo se multiplica de un modo incalculable (Navarro-Daniels, 2002, p. 409).

Yerma es un intertexto muy bien elegido, ya que esta obra trata el tema de la maternidad, aunque Yerma no pueda tener hijos.

El texto está puesto en boca de Huma, pero claramente es Manuela la que ha vivido esa situación del hijo muerto en la calle. La manera de presentar el sufrimiento sobre un escenario lo intensifica mucho más; así lo cree Jean-Max Méjean, que reflexiona muy acertadamente sobre esto en el siguiente fragmento:

El mundo es, pues, el lugar por excelencia del sufrimiento, sobre todo del sufrimiento por amor. Pero existen lugares más propicios para la ensoñación y la revelación del ser profundo; uno de ellos es la escena. Y por escena debemos entender la palabra en sentido amplio: todo aquel lugar que realza al personaje y le permite revelarse a sí mismo y a los demás. Este es el motivo por el que Pedro Almodóvar nos muestra a menudo a personajes llorando entre el público y mirando un espectáculo en el escenario, como en Tacones lejanos, Hable con ella y Todo sobre mi madre (2007, p. 142).

Recuérdese la escena en que Manuela ve el cartel de Un tranvía llamado deseo en un periódico -otro mecanismo de metaficción- y rememora el día del teatro con su hijo. En esta ocasión va al teatro, pero está sola, la butaca que ocupaba su hijo está vacía, lo que hace que Manuela sufra y se emocione aún más mientras ve la obra.

\footnotetext{
${ }^{9}$ En cursiva el texto perteneciente al acto tercero de Yerma, de Federico García Lorca.
} 


\section{Conclusiones}

Cuando el niño de Rosa logra negativizar el virus, Manuela dice que "es un milagro"; este niño milagroso vuelve a conectar con el niño Jesús del cuadro de Chagall y con la Sagrada Familia. Todo está perfectamente unido en la película, cada intertexto ayuda a caracterizar a los personajes. El mecanismo metaficcional funciona enmarcando la ficción dentro de la propia película, que ya es ficción, lo que hace replantearse y cuestionarse la primera. Además, la ficción le permite a Almodóvar hacer un ejercicio de exploración dentro de su cine, reflexionando sobre el acto creador a partir de varias obras ficcionales que van apareciendo en el filme y retomando a personajes de otras de sus películas, conectando de nuevo la realidad, su realidad como director, con la ficción.

Todo sobre mi madre es una película dedicada a mujeres y actuada por mujeres, entre las que existen fuertes lazos de solidaridad, cariño y amor; mujeres que hacen el papel de actriz, de amante y de madre. No se olvide la dedicatoria final con la que el director cierra su película: "A Bette Davis, Gena Rowlands, Romy Schneider... A todas las actrices que han hecho de actrices, a todas las mujeres que actúan, a los hombres que actúan y se convierten en mujeres, a todas las personas que quieren ser madres. A mi madre". Esta dedicatoria resume muy bien algunos de los temas que se han comentado; por un lado, la metaficción -actrices que hacen de actrices- y, por otro, que ser madre no tiene por qué tener relación con lo biológico, sino con querer serlo.

Por otro lado, metaficción e intertextualidad, dos características básicas en la obra del director, aquí le sirven para plantear un modelo de maternidad y de familia diferentes de los establecidos, alejados de los roles tradicionales de padre y madre. La ficción siempre se anticipa a la realidad representada en la película, pero al final acaba siendo mucho más real que la realidad misma.

\section{Referencias bibliográficas}

Almodóvar, Pedro. (1999a). Todo sobre mi madre [película]. España-Francia: El Deseo.

Almodóvar, Pedro. (1999b). Todo sobre mi madre. Guion original de Pedro Almodóvar. Madrid: El Deseo.

Bajtín, Mijail. (1981). The Dialogic Imagination. Austin: University of Texas Press. 
Caparrós Lera, José María. (2001). El cine de fin de milenio: 1999-2000. Madrid: Ediciones RIALP.

Cifre Wibrow, Patricia. (2005). Metaficción y postmodernidad: interrelación entre dos conceptos problemáticos. Revista Anthropos. Huellas del Conocimiento, (208), 50-58.

Colmenero Salgado, Silvia. (2001). Pedro Almodóvar. Todo sobre mi madre. Estudio crítico. Barcelona: Ediciones Paidós Ibérica.

García Lorca, Federico (2002). Yerma. Poema trágico en tres actos y seis cuadros. Edición de Ildefonso-Manuel Gil. Madrid: Cátedra (Obra original de 1934).

Genette, Gérard. (1989). Palimpsestos. La literatura en segundo grado. Madrid: Taurus.

Jenkins, Henry. (2011). Transmedia 202: further reflections. Confessions of an Aca-Fan: The Official Weblog of Henry Jenkins [blog]. http://henryjenkins.org/blog/2011/08/defining_transmedia_further_re.html Consulta: 22/02/2019.

Kristeva, Julia. (1978). Semiótica 1 (José Martín Arancibia, trad.). Madrid: Fundamentos. (Obra original publicada en 1969).

Méjean, Jean-Max. (2007). Pedro Almodóvar. Barcelona: Ediciones Robinbook.

Navarro-Daniels, Vilma. (2002). Tejiendo nuevas identidades: La red metaficcional e intertextual en Todo sobre mi madre de Pedro Almodóvar. Ciberletras, (7), 388-413. http://www.lehman.cuny.edu/ciberletras Consulta: 22/02/2019.

Poyato, Pedro. (2006). De la construcción de un nuevo cuerpo textual, sexual y familiar en Todo sobre mi madre de Almodóvar. Trama y fondo: revista de cultura, (20), 59-70.

Real Academia Española y Asociación de Academias de la Lengua Española. (2014). Diccionario de la lengua española (23. a edición). Madrid: Espasa.

Sardá, Juan. (2008). Mis influencias han sido Andy Warhol y Lola Flores. El cultural, 13-19 de noviembre, $76-82$.

Siles Ojeda, Begoña. (2008). Analizar todo sobre mi madre. Trama y fondo, (25), 160-161.

Waugh, Patricia. (1984). Metafiction. The Theory and Practice of Self-Conscious Fiction. Nueva York: Methuen. 